\title{
Protein-Carbohydrate Interaction
}

\section{The Interaction of Concanavalin A with Dextrans from \\ L. mesenteroides B-512-F, L. mesenteroides (Birmingham),}

\section{Streptococcus bovis, and a Synthetic $\alpha-(1 \rightarrow 6)$-D-Glucan. ${ }^{1,4}$}

\author{
I. J. GOLDSTEIN, ${ }^{2}$ R. D. PORETZ, ${ }^{3}$ L. L. SO, AND Y. YANG \\ Department of Biological Chemistry, The University of Michigan, Ann Arbor, Michigan 48104
}

Received March 25, 1968; accepted May 21, 1968

\begin{abstract}
The precipitation reaction between concanavalin A, the jack-bean hemagglutinin and several dextrans has been examined by means of the quantitative precipitin technique. A synthetic linear $\alpha-(1 \rightarrow 6)$-D-glucan did not form a precipitate with concanavalin A, demonstrating that only branched $\alpha$-D-glucans precipitate with the protein.

The dextran from Streptcoccus bovis produced a typical precipitation curve with concanavalin $\mathrm{A}$ and gave the disaccharide nigerose when subjected to acetolysis. On the basis of these data it is suggested that this dextran, hitherto believed to be linear, is in fact a branched polymer.

The concanavalin A precipitation curves of the dextrans from Leuconostoc mesenteroides NRRL B-512-F and Betacoccus arabinosaceous (L. mesenteroides) Birmingham strain were compared with the $S$. bovis dextran and an attempt has been made to correlate these data with the molecular structures of these dextrans. The differences in the solubility of the dextran-concanavalin A precipitates and the relative ease of inhibition of these systems in the presence of hapten inhibitor are also discussed.
\end{abstract}

Previous studies in this series have been concerned with the isolation, purification $(1,2)$ and characterization $(3,4)$ of concanavalin A (the jack-bean hemagglutinin) and its interaction with simple (5-8) and complex carbohydrates (9-13). We have observed that concanavalin A exhibits the properties of a multivalent (recently shown in this laboratory to be

${ }^{1}$ A preliminary report of this work appears in the Abstracts Volume, Seventh International Congress of Biochemistry, Tokyo, Aug. 1967.

${ }^{2}$ Established Investigator of the American Heart Association.

${ }^{3}$ Present address: Lister Institute of Preventive Medicine, Chelsea Bridge Road, London S.W. 1 England.

${ }^{4}$ This research was supported hy grants from the National Institutes of Health (AM-10171) and the Corn Industries Research Foundation, Inc. bivalent (14)) antibody-like protein which interacts to form a precipitate with a specific group of ramified polysaccharides $(5,6,9-13)$ which contain $\alpha$-D-glucopyranosyl, $\alpha$-D-mannopyranosyl or $\beta$-Dfructofuranosyl residues at their chain ends.

Quantitative hapten inhibition studies (5-7) with mono- and oligo-saccharides revealed the specificity of the proteincombining sites to be directed toward the C-3, C-4, and C-6 hydroxyl groups of the $\alpha$-D-gluco- or manno-pyranose rings, with the latter being the preferred form. These studies also confirmed that it is primarily the terminal, non-reducing glycosyl residues of polysaccharide chain ends with which concanavalin A interacts, although it has been shown that in the case of the disaccharide sophorose (2-O- 
$\beta$-D-glucopyranosyl-D-glucose), it is the C-3, C-4, and C-6 hydroxyl groups of the reducing $\mathrm{D}$-glucosido moiety with which the protein interacts (8). Our data also indicate that hydrogen bonds are importantly involved in stabilizing concanavalin A-carbohydrate complexes $(6,15)$.

Concanavalin A did not form a precipitate with several linear $\alpha$-D-glucans (amylose, nigeran, pullulan and isolichenan (9)); however, all 23 dextrans which were tested for their capacity to interact with concanavalin A formed precipitates. These results prompted us to suggest that all of these dextrans were branched and, in fact, that it was possible that all naturally occurring dextrans were branched (9).

Presently we are examining the feasibility of using concanavalin $\mathrm{A}$ as a reagent for studying the fine structures of polysaccharides. This report is concerned with an interpretation of the relationship between polysaccharide structure and the results obtained from quantitative precipitation studies of concanavalin A with several dextrans: dextran Leuconostoc mesenteroides NRRL B-512-F (16) (the source of clinical dextran); dextran Leuconostoc mesenteroides (Birmingham) $^{5}$ (17); the dextran from Streptococcus bovis (18), reported to be a linear polymer; and a chemically synthesized $\alpha$-(1 $\rightarrow$ 6)-D-glucopyranan (19) which has been shown by enzymic degradation (20) to contain a minimum of $98 \%$ $\alpha$-(1 $\rightarrow 6)$-D-glucosidic linkages.

\section{MA'TERIALS AND METHODS}

Dextran NRRL B-512-F was a gift of Dr. Allene Jeanes, Northern Research and Development Service, U.S. Department of Agriculture; the dextran from Leuconostoc mesenteroides (Birmingham) was obtained through the courtesy of Dr. S. A. Barker, University of Birmingham, England; the

\footnotetext{
${ }^{5}$ This organism has been variously referred to as Betacoccus arabinosaceous, Betacoccus arabinosaceous (Leuconostoc mesenteroides), Birmingham strain and Leuconostoc mesenteroides NRRL B-1375 (Birmingham). In this paper, the dextran produced by this organism will be referred to as the "Birmingham dextran."
}

dextran synthesized by Streptococcus bovis was a gift of Dr. H. Weigel, Royal Holloway College, England; and the synthetic $\alpha-(1 \rightarrow 6)$-D-glucopyranan was kindly provided by Dr. Conrad Schuerch, Syracuse University.

Methyl $\alpha$-D-glucopyranoside and $\beta$-D-glucose penta-acetate were purchased from Pfanstiehl Laboratories, Inc., Waukegan, Illinois. Silica gel G was obtained from Brinkmann Industries, Westburg, New York. Authentic samples of $\beta$-nigerose octaacetate and $\beta$-isomaltose octa-acetate were kindly provided by Dr. D. Horton, Ohio State University.

Concanavalin A was prepared hy the Sephadex procedure of Agrawal and Goldstein $(1,2)$. Quantitative precipitation and solubility studies were conducted by the method described by So and Goldstein (12) and quantitative hapten inhibition analyses were performed as described previously (6).

Solvent systems employed in paper chromatography were: Solvent 1: butanol:ethanol: water (4:1:5, v/v, upper phase) (21); Solvent 2: ethyl acetate : pyridine : water $(10: 4: 3, \mathrm{v} / \mathrm{v})(22)$.

Acetolysis of the $S$. bovis dextran was conducted by the procedure of Suzuki and Hehre (23).

Acetolysis of the dextran from $\mathrm{S}$. bovis. Dried dextran (387 $\mathrm{mg}$ ) was suspended with stirring in cold acetic anhydride $(4.0 \mathrm{ml})$. To this was added a mixture of cold acetic anhydride $(2.4 \mathrm{ml})$ and concentrated sulfuric acid $(0.8 \mathrm{ml})$. The reaction mixture was stirred in an iced water bath for $15 \mathrm{~min}$, allowed to stand with occasional shaking in a water bath $\left(43-54^{\circ}\right)$ for $4 \mathrm{hr}$, and then at $35^{\circ}$ for an additional $70 \mathrm{hr}$. The suspension (approximately $20 \%$ of the dextran remained insoluble) was poured into iced water $(120 \mathrm{ml})$ and stirred for $15 \mathrm{~min}$. Sodium bicarbonate was added slowly, with stirring, to $\mathrm{pH}$ 6. After extraction with chloroform $(5 \times 125 \mathrm{ml})$, the combined chloroform extracts were washed with $5 \%$ sodium bicarbonate solution $(5 \times 225 \mathrm{ml})$, water $(3 \times 150 \mathrm{ml})$, dried over anhydrous sodium sulfate and filtered. Thin-layer chromatography on Silica gel $\mathrm{G}$ with methanol-benzene $(4: 96, \mathrm{v} / \mathrm{v})$ indicated a series of components with mobilities similar to standard $\beta$-D-glucose penta-acetate, $\beta$-nigerose octaacetate and $\beta$-isomaltose octa-acetate, as well as components of lower mobility.

Deacetylation of the acetolysis mixture. The acetolysis mixture (in chloroform) was evaporated to a brown syrup, dried in a vacuum oven $\left(40^{\circ}\right)$ and weighed $(725 \mathrm{mg})$. After dissolution in chloroform $(6.0 \mathrm{ml})$, an aliquot $(3.0 \mathrm{ml})$ was removed, mixed with additional chloroform $(3 \mathrm{ml})$, methanol $(2 \mathrm{ml})$, sodium methoxide solution ( $80 \mathrm{mg}$ of sodium in 4 $\mathrm{ml}$ of methanol) and allowed to react under anhydrous conditions for $45 \mathrm{~min}$. Evaporation to dryness followed by addition of water $(15 \mathrm{ml})$ left a small 
quantity of undissolved material. The solution was immediately neutralized (Amberlite IR-120-cation exchange resin, $\mathrm{H}^{+}$form) filtered and evaporated to a syrup which was dissolved in absolute ethanol. The evaporation was repeated and the syrup was dried (vacuum oven, $40^{\circ}$ ) and weighed $(190 \mathrm{mg}$ ).

Preparative paper chromatography of oligosaccharides. An aqueous solution $(1 \mathrm{ml})$ of the oligosaccharide-mixture was applied to Whatman $3 \mathrm{MM}$ chromatography paper. The papers were irrigated (solvent 1) for 71 hours, and dried. Guide strips were cut, sprayed with alkaline silver nitrate reagent (24) and the areas corresponding to material of the same mobilities as nigerose (fraction A) and isomaltose (fraction B) were excised from the chromatogram. The saccharides were eluted with water and the solutions evaporated to clear syrups giving: fraction $\mathrm{A}(8.4 \mathrm{mg})[\alpha]_{\mathrm{D}}^{23}+143^{\circ}\left(c 0.84 ; \mathrm{H}_{2} \mathrm{O}\right)$; and fraction $B,(12.6 \mathrm{mg})$.

Paper chromatographic examination of fractions $A$ and $B$ (in solvent systems 1 and 2) showed fraction $B$ to have the same mobility as isomaltose and fraction $\mathrm{A}$ to migrate $\left(R_{G} 0.68,0.71\right.$, respectively in the above solvent systems) similarly to nigerose $\left(R_{G} 0.69,0.72\right)$ but differently from other $\alpha$-glucobioses (kojibiose, $R_{G} 0.57, \ldots$; maltose, $R_{G} 0.68$, 0.64 ; isomaltose, $0.46,0.48$ ).

Qualitative paper electrophoresis. Paper electrophoresis of fraction $\mathrm{A}(0.1 \mathrm{M}$ sodium tetraborate, $\mathrm{pH} \mathrm{10)}$ for $7.5 \mathrm{hr}$ at $100 \mathrm{~V}(23-32 \mathrm{~mA})$ followed by drying of the electrophoretogram and development with $p$-anisidine spray reagent (25) revealed that it had a mobility identical with that of nigerose ( $\left.M_{\text {maltose }} 1.7\right)$ but considerably greater than that of maltose ( $M_{\text {maltose }} 1.0$ ).

Acetylation of fraction $A$. Fused sodium acetate (20 $\mathrm{mg})$ and fraction $\mathrm{A}(6 \mathrm{mg})$ were dissolved in acetic anhydride $(1.5 \mathrm{ml})$ with heating $\left(85-125^{\circ}\right)$ over a period of $0.5 \mathrm{hr}$. The solution was cooled, poured into iced water $(10 \mathrm{ml})$ and stirred overnight at $5^{\circ}$. The aqueous solution was extracted with chloroform $(3 \times 15 \mathrm{ml})$ and the chloroform extract washed with water $(3 \times 25 \mathrm{ml})$ and evaporated to a straw-yellow syrup $(8 \mathrm{mg})$. The syrup was dissolved in hot ethanol and upon prolonged cooling, produced a small quantity of crystalline material, m.p. $110-112^{\circ}[\alpha]_{D}^{23}+77^{\circ}\left(\right.$ c $\left.0.68 ; \mathrm{CHCl}_{3}\right)$. Goldstein and Whelan (26) reported m.p. $152-153^{\circ}$ and $[\alpha]_{D}^{23}+83^{\circ}$ (c $1.3 ; \mathrm{H}_{2} \mathrm{O}$ ). Barker et al. (27) cited a melting point of $111-113^{\circ}$ for $\beta$-nigerose octa-acetate.

Poriodate oxidation of dextran NRRL B-512-F and $\mathrm{S}$. bovis dextran. An aqueous solution of polysaccharide $(100 \mathrm{mg} / 25 \mathrm{ml})$ was mixed with a solution of $0.35 \mathrm{~N}$ sodium metaperiodate $(10.0 \mathrm{ml})$ and diluted with water to $50.0 \mathrm{ml}$. The reaction mixture was allowed to proceed in the dark, at $4^{\circ}$ for 5 days. To determine periodate consumption, aliquots $(1.5$ $\mathrm{ml}$ ) were withdrawn periodically, added to a solution containing $30 \%$ potassium iodide $(2 \mathrm{ml}), 2 \mathrm{~N}$ sulfuric acid $(2 \mathrm{ml})$ and deionized water $(10 \mathrm{ml})$. The browish-red solution was covered and allowed to stand in the dark for $5 \mathrm{~min}$ and titrated with standard sodium thiosulfate solution $(0.109 \mathrm{~N})$, utilizing starch as an indicator. The formic acid released during oxidation was determined periodically on aliquots $(1.5 \mathrm{ml})$ removed from the reaction flask These were added to a solution of ethylene glycol $(0.5 \mathrm{ml})$ in deionized water $(10 \mathrm{ml})$, stored in the dark for $25 \mathrm{~min}$, and mixed with $30 \%$ potassium iodide (2 $\mathrm{ml}$ ). The solutions were covered, allowed to stand in the dark for $5 \mathrm{~min}$ and titrated with standard sodium thiosulfate $(0.011 \mathrm{~N})$ to the first starch end-point.

\section{RESULTS}

Quantitative precipitation curves for the interaction of concanavalin A with the three microbial dextrans examined in this study are shown in Figs. 1, 2, and 3. The $S$. bovis and B-512-F dextrans were far less reactive than dextran NRRL B1355-S, the dextran employed in our assay system (12). Thus, whereas dextran B-1355-S precipitated at the point of maximum precipitation, $41(98 \%)$ of the $42 \mu \mathrm{g}$ of concanavalin A nitrogen in the incubation mixture, it was necessary to add substantially more concanavalin A (approximately $139 \mu \mathrm{g} \mathrm{N}$ ) to obtain a reliable precipitation curve for the $S$. bovis

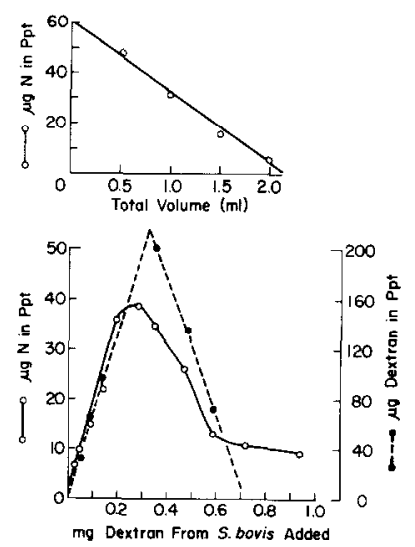

FIG. 1. Quantitative precipitation curve of the $S$. bovis dextran with concanavalin A. The total amount of dextran in the precipitates is also illustrated. Concanavalin A, $139 \mu \mathrm{g}$ of nitrogen. The solubility of the concanavalin A-S. bovis dextran is also demonstrated. 

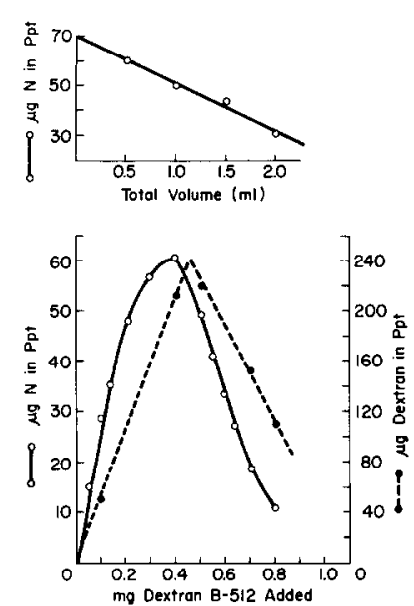

FIG. 2. Quantitative precipitation curve of dextran B-512-F with concanavalin A. The total amount of the dextran in the precipitates is also illustrated. Concanavalin A, $155 \mu \mathrm{g}$ of nitrogen. The solubility of the concanavalin A-B-512-F dextran is also demonstrated.
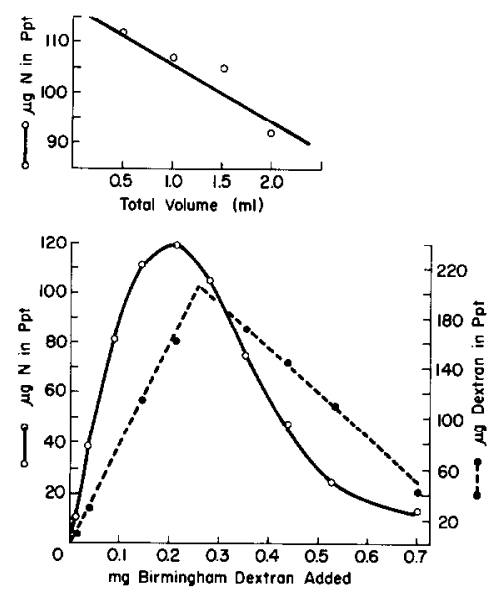

FIG. 3. Quantitative precipitation curve of the Birmingham dextran with concanavalin A. The quantity of the dextran in the precipitates is also illustrated. Concanavalin A, $144 \mu \mathrm{g}$ of nitrogen. The solubility of the concanavalin A-Birmingham dextran is also demonstrated.

dextran, which precipitated only $39 \mu \mathrm{g}$ $(28 \%)$ of the nitrogen added. Similarly, dextran B-512-F maximally precipitated only $60 \mu \mathrm{g}$ (39, $c$ ) of the $155 \mu \mathrm{g} \mathrm{N}$ added. In contrast, the dextran elaborated by $L$. mesenteroides (Birmingham) was considerably more reactive, precipitating 120 $\mu \mathrm{g}(83 \%)$ of the $144 \mu \mathrm{g}$ concanavalin A nitrogen added to the reaction mixture.
Table I demonstrates the unreactivity of the synthetic $\alpha-(1 \rightarrow 6)$-D-glucan. Even at a level of $141 \mu \mathrm{g} \mathrm{N}$ (3.5 times that at which dextran B-1355-S precipitates $98 \%$ of the added concanavalin A) (12) the synthetic polyglucose did not precipitate concanavalin A. This is of course not surprising inasmuch as this polysaccharide is believed to be a linear polymer $(19,20)$ and hence incapable of forming a threedimensional lattice with concanavalin A.

Only about $50^{\circ} \%$ of the $S$. bovis and B$512-\mathrm{F}$ dextrans added were found in the precipitates at the point of maximum nitrogen precipitation. In the case of the Birmingham dextran this figure is considerably higher, being approximately $79{ }^{\circ}$. It will be recalled (12) that concanavalin A precipitated virtually all of the dextran B-1355-S added, up to and throughout the "equivalence zone."

The solubility of the dextran-concanavalin A precipitates (at the point of maximum nitrogen precipitation) is a very revealing parameter. Compared to the dextran B-1355-S-concanavalin A precipitate which had a solubility of $1.5 \mu \mathrm{g} \mathrm{N}$ per $\mathrm{ml}(12)$, the solubility of the $S$. bovis dextran-concanavalin A precipitate was $28 \mu \mathrm{g} \mathrm{N}$ per ml (Fig. 1), that of dextran B-512-F-concanavalin A precipitate, 19 $\mu \mathrm{g} N$ per $\mathrm{ml}$ (Fig. 2) and that of the Birmingham dextran-concanavalin A precipitate, $11 \mu \mathrm{g} \mathrm{N}$ per $\mathrm{ml}$ (Fig. 3). The significance of these solubility differences in terms of molecular structure will be discussed below.

Quantitative hapten inhibition studies employing the three dextrans as the precipitating polysaccharide are shown in Fig. 4. The extent (percentage inhibi-

\section{TABLE I}

Interaction of Concanavalin A with a Synthetic, Linear $\alpha-(1 \rightarrow 6)$-DGLuCAN (19)

\begin{tabular}{ccc}
\hline $\begin{array}{c}\text { Concanavalin A } \\
(\mu \mathrm{g} \text { nitrogen })\end{array}$ & Dextran $(\mathrm{mg})$ & $\begin{array}{c}\text { Nitrogen in } \\
\text { precipitate }(\mu \mathrm{g})\end{array}$ \\
\hline 141 & 0.45 & 0.1 \\
141 & 0.91 & 0 \\
141 & 1.36 & 0 \\
141 & 1.81 & 0 \\
\hline
\end{tabular}




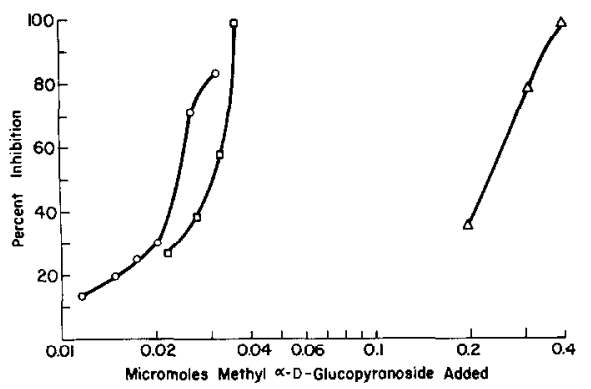

FIG. 4. Inhibition of precipitation of concanavalin A-dextran interaction by methyl $\alpha$-D-glucopyranoside. ( $\odot$ ), S. bovis dextran; ( $\square$ ), dextran B-512-F; $(\triangle)$, Birmingham dextran.

tion) to which methyl $\alpha$-D-glucopyranoside inhibited precipitation of the respective systems is plotted against the concentration of this glycoside in micromoles on a logarithmic scale. It is apparent that the $S$. bovis and B-512 dextran systems are much more readily inhibited than the concanavalin A-Birmingham dextran system, the quantities of methyl $\alpha$-D-glucopyranoside required to produce $50 \%$ inhibition being 0.024 , 0.03 , and $0.22 \mu$ moles, respectively.

The similarity in the structures of the dextrans from $S$. bovis and $L$. mesenteroides NRRL B-512-F is shown by the similar behavior of both polysaccharides during controlled periodate oxidation. Thus, both glucans released 0.95 moles of formic acid/mole glucosyl residue and consumed 2.01 (S. bovis) and 1.90 (B-512F) moles of periodate/mole glucosyl residue after 8.6 and $8.3 \mathrm{hr}$ of reaction time, respectively. These results may be compared to those of Rankin and Jeanes (28) who reported that dextran B-512-F, during oxidation, released 0.95 moles of formic acid and consumed 1.94 moles of periodate/mole glucosyl unit. Similarly, Bailey (18) reported a value of 2.00 moles of periodate consumed $/ \mathrm{mole}$ of glucosyl residue during the oxidation of the dextran from $S$. bovis.

A comparison of the properties of authentic nigerose with the nigerose isolated by acetolysis from the $S$. bovis dextran established the identity of the isolated material.

\section{DISCUSSION}

The present study confirms our previous investigations by: (1) demonstrating that a synthetic linear $\alpha-(1 \rightarrow 6)$-D-glucan (17) containing a minimum of $98 \% \alpha-(1 \rightarrow$ 6)-D-glucosidic linkages as deduced by enzymatic degradation (20) did not form a precipitate with concanavalin $\mathrm{A}$, even at protein levels which brought about the precipitation of all the naturally occurring dextrans which we have examined; and (2) showing that the dextran from $S$. bovis, reported by several criteria to be linear (18) is almost certainly branched.

From an examination of the polyglucoses produced by several strains of rumen $S$. bovis grown on sucrose and $\mathrm{HCO}_{3}{ }^{-}$ ion, Bailey (18) stated these polysaccharides are unbranched $\alpha$-D-glucans possessing solely $\alpha-(1 \longrightarrow 6)$-D-glucosidic linkages. These conclusions were based primarily on: (1) partial acid hydrolysis studies in which isomaltose was the only disaccharide identified; (2) controlled oxidation with sodium periodate, which produced results that were very close to those expected for a linear $(1 \rightarrow 6)$-glucan and $(3)$ the absence of the infrared absorption band $(12.6 \mu)$ believed to be characteristic of $\alpha-(1 \rightarrow 3)$-linkages $(16,29)$.

Inasmuch as concanavalin A formed a precipitate with the $S$. bovis dextran, an indication of branching in the polymer, we undertook an examination of the structure of this polysaccharide, by techniques other than those used by Bailey (18). It is well documented that acid hydrolysis preferentially destroys $\alpha-(1 \rightarrow 2)$, $\alpha$ - $(1 \rightarrow 3)^{-}, \quad$ and $\alpha$ - $(1 \rightarrow 4)$-D-glucosidic bonds as compared to $\alpha$ - $(1 \rightarrow 6)$-linkages (30). Therefore, a glucan containing only small proportions of non- $\alpha-(1 \rightarrow 6)$-Dglucosidic units would not be expected to yield, upon partial acid hydrolysis, disaccharides characteristic of these structural features, i.e., kojibiose, nigerose, and maltose. However, acetolysis has been shown to cleave $\alpha$-(1 $\rightarrow 6)$-linkages considerably more readily than linkages in- 
volving secondary hydroxyl groups of glycosyl residues $(23,26,31-35)$.

Indeed, nigerose, in a minimum yield of $4 \%$, was isolated from a deacetylated acetolysis mixture of the $S$. bovis dextran. The properties of this disaccharide compared very favorably with an authentic sample of nigerose and this disaccharide undoubtedly represents a structural feature of the polysaccharide. Although it is probable that a portion of the nigerose isolated represents branch-point linkages, it is known that linkages other than those involving $\alpha$-( $1 \rightarrow 6)$-D-glucopyranosidic bonds occur in linear portions of dextran molecules; e.g., we have evidence that dextran B-1355-S contains $\alpha$ $(1 \rightarrow 3)$-glucosidic linkages in the linear portion of the dextran molecule (cf. Ref. 36).

In a comparison of the periodate oxidation of the dextrans from $S$. bovis and $L$. mesenteroides NRRL B-512-F (which has been shown by methylation studies to possess $96 \%_{\circ}^{\circ} \alpha-(1 \rightarrow 6)$ - and $4 \% \alpha-(1 \rightarrow 3)$ D-glucosidic bonds) (37), it is interesting to note that similar if not identical results were obtained with regard to both periodate consumption and release of formic acid. It is apparent, therefore, that acetolysis is a considerably more productive technique for obtaining evidence for the existence of a small proportion of $\alpha$ $(1 \rightarrow 3)$-D-glucosidic linkages in polysaccharides. Jeanes et al. (16) regarded $2 \%$ as the limit of detection of such units by measurement of periodate consumption and formic acid release. Suzuki and Hehre (23) in an examination of the acetolysis of a variety of dextrans noted that ten preparations, which yielded from $0.4-2.9^{\circ}$, nigerose, showed no $(1 \rightarrow 3)$-like residues by periodate oxidation. These workers also reported that acetolysis of dextran NRRL-B-742-L yielded $1.1 \%$ nigerose. This is especially interesting inasmuch as this polysaccharide has been regarded as essentially free of $(1 \rightarrow 3)$-linkages and therefore was employed as the zero standard in infrared spectrophotometric analysis for $(1 \rightarrow 3)$-linkages in polysaccharides (absorption band at $12.6 \mu$ ) $(16,29)$.
The precipitation curves (Figs. 1, 2, and 3) for the three microbial dextrans examined are typically bell-shaped. The Birmingham dextran was the most reactive of the three in terms of maximum concanavalin A nitrogen precipitated $(83 \%)$ and carbohydrate brought down in the precipitate $\left(79^{c}\right)$. If one corrects for the solubility $(11 \mu \mathrm{g} \mathrm{N} / \mathrm{ml})$ of the precipitate (neglecting the two washings of the precipitate), it is possible to account for $92 \%$ of the concanavalin $\mathrm{A}$ in the incubation mixture.

On the other hand, the $S$. bovis and B-512-F dextrans precipitated, at the point of maximum precipitation, only 28 and $39 \%$, respectively, of the concanavalin A nitrogen and less than $50 \%$ of the dextran present in the initial reaction mixtures.

Although we have accumulated considerable information on the factors which influence polysaccharide-concanavalin A interaction, i.e. molecular weight of the polysaccharide, frequency and nature of the branching, character of the linkage joining the terminal, nonreducing glycosyl unit to the succeeding (subterminal) unit, i.e. $(1 \rightarrow 6),(1 \rightarrow 4)$, etc. and number of units in the exterior chains, there is still much to learn.

Nevertheless it is possible to make some interpretations of these data in terms of the molecular structure of the dextrans. The dextran elaborated by $L$. mesenteroides (Birmingham) was shown by methylation studies (37) to have a branch point for every 6 to 7 D-glucosyl residues; furthermore, the branch points were shown to arise from $(1 \rightarrow 3)$-glucosidic linkages and it was calculated that more than $18 \%$ of all branches consist of a single glucosyl unit (38-40). This makes it approximately three times more ramified than B-512-F dextran, which contains one branch for every 23 units (37). Nothing is known concerning the extent of branching of the $S$. bovis dextran. It is to be noted that the more highly branched Birmingham dextran is the most reactive of the three dextrans with regard to its capacity to precipitate concanavalin A. The solubility of the concanavalin A- 
dextran precipitates also is lowest in the case of the Birmingham dextran (Fig. 3). Furthermore, the concanavalin A-Birmingham dextran system is the most difficult to inhibit (Fig. 4) in the presence of methyl $\alpha$-D-glucopyranoside, $0.22 \mu$ moles being required for $50 \%$, inhibition of precipitation compared to 0.025 and 0.030 $\mu$ moles of this glycoside to inhibit the B-512-F dextran- and the $S$. bovis dextran-concanavalin A systems, respectively.

It is believed that at least $70^{\circ}$, r of the branches in dextran B-512-F are only one unit long (36). It might be expected that the concanavalin A combining sites (which can accommodate one $\alpha$-D-glucosyl residue) would experience considerable hindrance in approaching a single glucosyl stub extending from a polysaccharide chain. One piece of data which supports this view is the inhibition data on 4,6 -di-( $\alpha$-D-glucopyranosyl)-D-glucose (the branch-point trisaccharide of glycogen and amylopectin). It was considered that this trisaccharide by virtue of its two non-reducing $\alpha$-glycosyl units would act as a "double-headed" inhibitor. In fact, it was shown to be somewhat less active than maltose, this being attributed to a steric effect; i.e., one can regard this substance either as an isomaltose derivative with a large substituent radical at $\mathrm{C}-4$ of the reducing glucose unit, or as a maltose molecule carrying a large radical at C-6 of the reducing glucosyl moiety. In either case the large $\alpha$-glucosyl substituent would be expected to offer hindrance to binding by the protein.

On the basis of the reactivity of the $S$. bovis dextran with concanavalin $\mathrm{A}$, and the presence of some $\alpha$ - $(1 \rightarrow 3)$-linkages as deduced from the isolation of nigerose, we conclude that this dextran is in many respects similar to dextran $\mathrm{B}-512-\mathrm{F}$ and probably is branched to a limited extent. The high solubility of the concanavalin A-S. bovis dextran precipitates and the great ease with which this system is inhibited support this conclusion.

We are presently investigating the interaction of concanavalin A with a large number of dextrans in the hope of defining further the structural parameters in- volved in polysaccharide-concanavalin A interaction.

\section{REFERENCES}

1. Agrawal, B. B. L., and Goldstein, I. J., Biochem. J. 96, 236 (1965).

2. Agrawal, B. B. L., and Goldstein, I. J., Biochim. Biophys. Acta 147, 262 (1967).

3. Agrawal, B. B. L., and Goldstein, I. J., Biochim. Biophys. Acta 133, 376 (1967).

4. Agrawal, B. B. L., and Goldstein, I. J., Arch. Biochem. Biophys. 124, 218 (1968).

5. Goldstein, I. J., Hollerman, C. E., and Smith, E. E., Biochemistry 4, 876 (1965).

6. So, Lucy L., and Goldstein, I. J., J. Immunol. 99, 158 (1967).

7. Smith, E. E., and Goldstein, I. J., Arch. Biochem. Biophys. 121, 88 (1967).

8. Goldstein, I. J., IyeR, R. N., Smith, E. E., AND So, L. L., Biochemistry 6, 2373 (1967).

9. Goldstein, I. J., Hollerman, C. E., and MerRICK, J. M., Biochim. Biophys. Acta 97, 68 (1965).

10. Goldstein, I. J., and So, Lucy L., Arch. Biochem. Biophys. 111, 407 (1965).

11. Goldstein, I. J., And Iyer, R. N., Biochem. Biophys. Acta 121, 197 (1966).

12. So, Lucy L., and Goldstein, I. J., J. Biol. Chem. 242, 1617 (1967).

13. So, Lucy L., and Goldstein, I. J., J. Biol. Chem. 243, 2003 (1968).

14. So, Lucy L., unpublished results.

15. Poretz, R. D., and Goldstein, I. J., Abstracts of Papers, 154th Meeting of the American Chemical Society, New York, September 1967, pp. 6P, 48D.

16. Jeanes, A., Haynes, W. C., Wilham, C. A., Rankin, J. C., Melvin, E. H., Austin, M. J., Cluskey, J. E., Fisher, B. E., Tsuchiya, H. M., And Rist, C. E., J. Am. Chem. Sac. 76, 5041 (1954).

17. Barker, S. A., Bourne, E. J., Bruce, G. T. Neeley, W. B., and Stacey, M., J. Chem. Soc. 2395 (1954).

18. Bailey, R. W., Biochem. J. 71, 23 (1959).

19. Ruckel, E. R., And Schuerch, C., J. Am. Chem. Soc. 88, 2605 (1966).

20. Reese, E. T., and Parrish, F. W., Biopolymers 4, 1043 (1966).

21. Partridge, S. M., and Westall, R. G., Biochem. J. 42, 238 (1948).

22. Whistler, R., And Hickson, L., Anal. Chem. 27, 1514 (1955).

23. Suzuki, H., and Hehre, E. J., Arch. Biochem. Biophys. 104, 305 (1964).

24. Trevelyan, W. E., Proctor, D. P., and HarRISON, J. S., Nature 166, 444 (1950).

25. Hough, L., Jones, J. K. N., and Wadman, W. H., J. Chem. Soc. 1702 (1950). 
26. Goldstein, I. J., and Whelan, W. J., J. Chem. Soc. 170 (1962).

27. Barker, S. A., Bourne, E. J., and Stacey, M., J. Chem. Soc. 3084 (1953).

28. Rankin, J. C., and Jeanes, A., J. Am. Chem. Soc. 76,4435 (1954).

29. Burket, S. C., and Melvin, E. H., Science 115, 576 (1952).

30. BeMiller, J. N., Advan. Carbohydrate Chem. 22, 25 (1967).

31. Whelan, W. J., Bull Soc. Chim. Biol. 42, 1569 (1960).

32. Matsuda, K., Watanabe, H., Fujimoto, K., AND Aso, K., Nature 191, 278 (1961).

33. Matsuda, K., Fujimoto, K., and Aso, K., J. Agr. Chem. Soc. Japan 35, 1232 (1961) (in Japanese).
34. Guthrie, R. D., and McCarthy, J. F., Advan. Carbohydrate Chem. 22, 20 (1967).

35. Jones, J. K. N., ANd Nicholson, P., J. Chem. Soc. 27 (1958).

36. Jeanes, A., in "Third Conference on Polysaccharides in Biology" (G. F. Springer, ed.), pp. 140-141. Josiah Macey, Jr. Foundation, New York 1957.

37. Van Cleve, J. W., Schaefer, W. C., and Rist, C. E., J. Am. Chem. Soc. 78, 4435 (1956).

38. Bourne, E. J., Hutson, D. H., and Weigel, H., Biochem. J. 86, 555 (1963).

39. Hutson, D. H., and Weigel, H., Biochem. $J$. 88, 588 (1963).

40. Aввотt, D., Bourne, E. J., and Weigel, H., $J$. Chem. Soc. 828 (1966). 